\title{
LA ACCIÓN DE NULIDAD POR USO PREVIO DE UN SIGNO DISTINTIVO. LA MARCA DE HECHO EN LAS LEGISLACIONES ARGENTINA Y MEXICANA
}

A AÇÃO DE NULIDADE POR USO PRÉVIO DE UM SINAL DISTINTIVO: A MARCA DE FATO NAS LEGISLAÇÕES ARGENTINA E MEXICANA

THE ACTION OF NULLITY FOR PRIOR USE OF A DISTINCTIVE SIGN: THE TRADEMARK IN THE ARGENTINIAN AND MEXICAN LEGISLATIONS

Marta Carolina Giménez Pereira ${ }^{1}$

Resumen: El objetivo del presente trabajo es realizar una descripción general del panorama actual de una figura típica de la Propiedad Industrial, cual es la marca, aquí estudiada en su excepción legal de registro y que se halla prevista en algunas legislaciones con los nombres de Marca de Hecho o Uso Previo o Derecho de Precedencia, denominación que adopta según los países que se analizarán, a saber, Argentina, México y, citando solo someramente, Brasil. El estudio abarca la regulación de la

1 Doctora en Derecho por el Instituto de Investigaciones Jurídicas, UNAM, México. Becaria PNPD CAPES en el PPGDireito IMED. Línea de investigación: Mecanismos de efectuación de la democracia y de la sostenibilidad. Grupo de investigación: Derecho, Nuevas Tecnologías y Desarrollo. Grupo de Investigación GEDIPI. Email: magipe@hotmail.com 
figura en México y su vinculación con la jurisprudencia de Argentina, exponiendo el interés jurídico de la misma y sus efectos ante la acción de nulidad del registro marcario que queda nulificado mediante acción legal en caso de la excepción citada. También se citan otros aspectos genéricos utilizando un método comparativo, deductivo y de investigación bibliográfica.

Palabras clave: Acción de Nulidad; Derecho de Precedencia; Marca de Hecho; Uso Previo.

Resumo: O objetivo do presente trabalho foi realizar uma descrição geral do panorama atual de uma figura típica da Propriedade Industrial, qual seja, a marca, aqui estudada na sua exceção legal de registro e que se encontra prevista em algumas legislações sob o nome de Marca de Fato ou Uso Prévio ou Direito de Precedência, denominação adotada segundo os países que serão analisados, sendo eles a Argentina, o México e, citando só brevemente, o Brasil. O estudo abrange a regulação da figura no México e a sua vinculação com a jurisprudência da Argentina, expondo o interesse jurídico da mesma e seus efeitos diante da ação de nulidade do registro marcário, que fica nulificado mediante ação legal no caso da exceção citada. Citam-se também outros aspectos genéricos, utilizando um método comparativo, dedutivo e de pesquisa bibliográfica.

Palavras-chave: Ação de nulidade; Direito de precedência; Marca de fato; Uso prévio.

Abstract: The aim of this work was to give a general description of the current panorama of a typical figure of Industrial Property, the trademark, studied here in its legal exception of registration, and which is provided for in some legislations under the name of Marca de Fato (Trademark) or Uso Prévio (Prior Use), or Direito de Precedência (Law of Precedence), a name adopted according to some countries that will be analyzed: Argentina, Mexico, and with a brief mention, Brazil. The study includes the regulation of the figure in Mexico, and its link with the jurisprudence of Argentina, demonstrating the legal interest of the same and its effects before the action of nullity of the registered trademark, which is nullified through 
legal action in the case of the exception cited. Other generic aspects are also cited, using a comparative, deductive method, and bibliographic research.

Keywords: Action of nullity; Right of Precedence; Marca de fato; Prior Use.

\section{INTRODUCCIÓN}

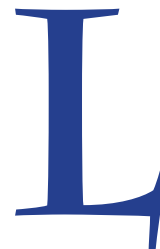

a vía usual por la que se protege un signo distintivo y que denota la existencia de un derecho de propiedad industrial es a través del otorgamiento de un registro y en consecuencia el reconocimiento de tales derechos por la legislación respectiva, conforme a la cual ha agotado un proceso de inscripción ante una instancia administrativa. Empero, a diferencia de la marca registrada, existe, además, la denominada "marca de hecho" (Argentina y otros países), también llamada "de uso previo" (México), que son aquellos signos que se utilizan con la misma función distintiva propia de esas marcas, sin haber sido registrados como tales, pero sin por ello importar un permiso de violación de los derechos de las registradas, condición fundamental para que las mismas no se encuentren dentro del supuesto de las marcas usadas ilícitamente, que tienen consecuencias jurídicas muy diferentes a aquellas.

Encuentran un fundamento en una repetida jurisprudencia y la doctrina de los autores que se han inclinado en el sentido de otorgar protección legal a las marcas como si tuviera un tinte del otro sistema, el denominado "declarativo", en el que la exclusividad sobre una marca se logra primeramente con el uso, y el registro viene a ser entonces una mera consecuencia. Aquí analizamos entonces, como se mencionó, la figura que, en consecuencia, surge y que se denomina "marca de hecho" o "uso previo", realizando además y finalmente una breve referencia a la situación de esta figura en Brasil.

\section{ACCIÓN DE NULIDAD POR LA MARCA DE HECHO O USO PREVIO DE}

UNA MARCA

La doctrina establece que la marca es aquel signo distintivo que sirve para diferenciar en el mercado un producto o un servicio. Su fundamento e importancia 
radican en que el agente económico interviniente tiene razones suficientes para creer que el producto que comercializa o el servicio que presta son preferibles a los de sus ocasionales rivales económicos y busca en consecuencia individualizarlos de tal forma que puedan distinguirse y no resulten confundidos, para lo cual acude así a la protección marcaria. Por ello, existe una estrecha correlación entre la decisión de adquirir, en principio, una propiedad de una marca y la de defenderla².

En el registro de marca en varios países que aplican el "civil law", entre ellos México y Argentina, se ha adoptado para la protección de las mismas el sistema "atributivo", a través del cual se otorga el derecho de propiedad industrial a quien registra la marca y prácticamente no es posible invocar derechos si no se cuenta con el registro previo.

En la legislación argentina no se ha contemplado esta figura expresamente y solo la ha reconocido la jurisprudencia. En efecto, el artículo 4 de la actual ley de marcas señala que la propiedad de una marca y la exclusividad de uso se obtienen con su registro y la ley penal de este país solo protege a aquellas marcas que han sido registradas ${ }^{3}$.

Si bien el uso de la marca es libre, vale decir, no se necesita contar con un registro para su uso, el mismo carece de protección en tanto no sea registrado, por lo que cualquier tercero podrá hacer uso de la misma al considerar que solo el registro es el que otorga a su titular el derecho de exclusividad de uso en forma excluyente. Dicho de otro modo, el derecho a usar una marca únicamente por su titular o por terceros por él autorizados y el derecho de impedir su uso por parte de terceros no autorizados lo confiere solamente el registro, que cumple la finalidad de otorgar protección efectiva al signo distintivo, tal como lo prevé para el efecto el artículo 2 de la Convención Colombo Francesa de 1901.

2 Bertone, Luis Eduardo y Cabanellas de las Cuevas, Guillermo, Derecho de marcas. Marcas, designaciones y nombres comerciales, $2^{a}$ edición actualizada, corregida y aumentada, Buenos Aires: Heliasta, 2003, tomo I, 2003, p. 311, 322.

3 Además, el artículo 4 última parte de la Ley 22.362, asevera: "para ser titular de una marca o para ejercer el derecho de oposición a su registro o a su uso, se requiere un interés legítimo del solicitante o del oponente" lo cual es aplicable al que peticiona la caducidad por falta de uso, tema que no abordaremos en este trabajo. 
Sin embargo, una sostenida jurisprudencia, así como la doctrina de los autores, se ha volcado en el sentido de otorgar protección legal a las marcas de hecho o de uso previo, como si tuviera un tinte del otro sistema, el denominado "declarativo", en el que la exclusividad sobre una marca se logra primeramente con el uso y el registro viene a ser entonces una mera consecuencia.

La regulación de esta figura, como excepción al sistema atributivo vigente en los países occidentales, se ha ido logrando en forma paulatina y, al respecto, recuérdese que los titulares de las denominadas marcas de hecho o de uso previo ostentan un derecho de propiedad sobre tal signo, ante lo cual no obsta "la circunstancia de que no se encontrare registrado a su nombre"4.

Sabiendo entonces que el propietario -productor, fabricante, comerciante o prestador de servicios- de la marca tiene el derecho a registrarla o a no registrarla, operada la elección del signo individualizante, puede escoger entre su uso como simple marca de hecho o de uso previo, cuya protección en el sistema jurídico de los países que adoptan el sistema atributivo es, como se ha dicho, limitada; o bien intentar conseguir el jus prohibendi o exclusividad de uso sobre el signo, tramitando el pertinente registro ante la autoridad administrativa correspondiente. He aquí la distinción entre el "hecho" y el "derecho" marcarios 5 .

La marca de hecho o de uso previo cumple una tarea fundamental en el aspecto procesal pues el actor, a través de la vía de la nulidad, tiene opción de reivindicar su derecho frente a una injusta pretensión por parte de un tercero.

Desde este punto de vista, la marca de hecho o de uso previo consiste en una singular figura que otorga la posibilidad legal del reconocimiento de un derecho a aquel que no ha procedido al registro de su marca y que la está utilizando, respecto de aquel que sí ha efectuado el trámite de registro y ha obtenido la protección de su marca.

4 Cfr. Jurisprudencia argentina: CNFed. Civ. y Com., Sala I, Febrero 5-988, Causa Busquier, A.E. c/ González, J., LL, 1988-E, pág. 308.

5 Bertone, Luis Eduardo y Cabanellas de las Cuevas, Guillermo, Derecho de marcas. Marcas, designaciones y nombres comerciales, $2^{a}$ edición actualizada, corregida y aumentada, Buenos Aires: Heliasta, 2003, tomo II, 2003, p. 19. 
Se constituye en un derecho de prelación o mejor derecho en el tiempo frente a un tercer pretensor si la fecha es anterior a la denominada "fecha legal", que es la de la solicitud de registro, o en su caso la "fecha de primer uso".

A fin de probar el uso del signo distintivo, es posible presentar como evidencia productos, facturas o incluso la publicidad, siempre y cuando corresponda a una época anterior al que sea titular de la marca jurídicamente hablando, siendo precisamente esta su principal característica, la de carecer de titular o dueño, y también siempre y cuando se compruebe su uso por un período considerable de tiempo, vale decir extenso o prolongado, requisito indispensable y justificación de acción válida contra una marca registrada idéntica o similar.

Solo es posible invocarla a través de la acción de nulidad, la que para este caso prescribe a los tres años de concedido el registro que se considera espurio y tiene por último objeto obtener el registro de la marca en disputa, invocando el precepto legal correspondiente, el que enseguida enunciaremos y que corresponde a la legislación mexicana.

Por su parte, fiel a su criterio restrictivo en este ámbito, el derecho judicial argentino ha afirmado que no es dable reconocer al usuario de la marca de hecho un ámbito de tutela mayor que el que exhibe su propio uso, debiéndose además compatibilizar el reconocimiento del acceso a la titularidad de la marca con el derecho de terceros que han adquirido títulos legítimos y no cuestionados ${ }^{6}$, como veremos a continuación.

\section{LA MARCA DE HECHO EN ARGENTINA}

Desde el punto de vista normativo, en la historia de la legislación marcaria argentina, ni bajo su Ley $N^{\circ} 3.975$ de 23 de noviembre de 1900, que tomó como modelo la legislación de marcas francesa, ni bajo la actual Ley de Marcas y Designaciones N 22.362 del 26 de diciembre de $1980{ }^{7}$, se incluye 6 Cfr Jurisprudencia argentina: CN Civ. y Com. Fed. Sala I, Septiembre 6 1984; ED, 112-173.

7 Entre otras particularidades, esta ley se destaca por introducir la figura de la marca de servicio y establece como obligatorio el uso de la marca señalando como sanción la caducidad, tal como lo dispone su artículo 26: "A pedido de parte, se declarará la caducidad de la marca que no hubiera sido utilizada en el país, dentro de los cinco (5) años previos a la 
aun expresamente la figura en estudio, pero se prevé sin embargo no solo la protección de la marca ya utilizada, sobre todo cuando goza de cierto prestigio, sino inclusive de aquellas marcas de esta índole que hayan sido utilizadas por terceros no autorizados, entre los que se excluyen los de buena fe, como se detallará más adelante.

De hecho, como se anticipó, siguiendo fielmente el sistema atributivo, el artículo 4 de la legislación actual de marcas expresa: "La propiedad de una marca y la exclusividad de uso se obtienen con su registro". En este país, como fuente del derecho, es más bien la jurisprudencia la que se ha ocupado, a través de sus repetidos fallos, de lo que en ese país denominan marca de hecho y la Ley de Marcas reconoce indirectamente a la marca usada sin registro, es decir, la marca de hecho o de uso previo.

Dado que la marca no registrada en este caso viene a constituirse en una marca usada sin registro, la jurisprudencia argentina a través de un sinfín de casos le ha reconocido valor confiriéndole ciertos derechos frente a otra que se registre posteriormente, siguiendo los principios generales del Derecho y las normas civiles y con el fundamento de que los actos no pueden ser inmorales o contrarios a las buenas costumbres, a manera de defensa al propietario de la marca de hecho o de uso previo frente al que pretende despojarlo injustamente sobre todo del prestigio obtenido.

Así, se ha sostenido que tal figura "de excepción funciona cuando un tercero sin escrúpulos pretende inscribir una marca que es usada intensamente por quien no la ha registrado y tiende a evitar que se consuma un despojo contrario a la moral"8 y "obedece no sólo al propósito de evitar maniobras de mala fe de su contrario...sino también a los efectos de defender a una clientela formada mediante esa utilización"9.

fecha de la iniciación de la acción, salvo que mediaren causas de fuerza mayor. No caduca la marca registrada y no utilizada en una clase si la misma marca fue utilizada en la comercialización de un producto o en la prestación de un servicio incluido en otras clases, o si ella forma parte de la designación de una actividad".

8 Cfr Jurisprudencia argentina: Causa 3245, "Panificación Argentina SA vs Marcolla, León", sala entonces única, del 05/09/1967.

9 Cfr. Jurisprudencia argentina: Causa 9476, "R. Moghilevsky e Hijos SRL vs Madaus SACIFI", sala II, del 21/07/1970. 
Esta cuestión ha sido abordada por los tribunales de ese país y se ha sostenido que "el carácter atributivo de la Ley de Marcas no puede aplicarse con criterio rigurosamente formal, que prive a las marcas no registradas de la protección que surge de los principios generales del Derecho, sea para evitar prácticas desleales, sea para tutelar el derecho a una clientela formada por una actividad lícita cumplida durante muchos años"10.

Sobre el punto de los principios generales del derecho y por su importancia, se cita una sentencia en la que "...la jurisprudencia del Tribunal tiene establecido que el carácter atributivo que consagra la ley de marcas no puede ser aplicado con un criterio rigurosamente formal, que conduzca a negar a los signos no registrados la protección que puedan merecer según los principios generales del derecho. Y así, ha considerado que cuando un signo sin registro ha sido intensamente explotado $y$ a su sombra se ha formado una clientela, los principios que salvaguardan la buena fe, la moral y las buenas costumbres, la lealtad comercial y el ejercicio regular de las prerrogativas propias (arg. arts.21, 953, 1071, 1198 y 2514 del Código Civil), la hacen acreedora de tutela, en su carácter de marca de hecho..." ${ }^{11}$

Es de notar que con la sentencia antedicha hasta el derecho de prioridad pudiera verse quebrantado ante una marca de hecho o de uso previo ya que tal derecho será respetado solo frente a otras solicitudes presentadas en iguales condiciones mas no frente a casos excepcionales como la figura en análisis y el solo uso de una marca carente de registro ha sido motivo para lograr el éxito frente a una marca registrada posteriormente o para accionar invocando su nulidad e incluso rechazar una oposición deducida a la solicitud de su registro ${ }^{12}$.

Señala al respecto Otamendi que no siempre la presentación de la solicitud otorga a su titular un derecho absoluto de prioridad, de la misma manera que la marca concedida no otorga un derecho indiscutible e inatacable. Existen casos en los que una solicitud debe ceder ante marcas que ya han sido utilizadas con

10 Cfr. Jurisprudencia argentina: Causa 6921, "Swift de La Plata SA Frigorífica vs Sumastre, Gerardo", sala II, del 23/05/1978.

11 Cfr. Jurisprudencia argentina: Causa 11701/94, "Jacob Suchard SA c/ Alberto Fehrmann SA s/ cese de uso de marca", CNCIV Y COMFED, sala II, del 18/09/2003.

12 Cfr. Jurisprudencia argentina: Causa "Manufactura Forti Arg. SA vs Imperial Chemical Ind. Lim." del 17/06/1969. También el caso de juguetes Lionel's que se cita más adelante. 
anterioridad a dicha solicitud en virtud de que puede haber marcas que se hayan usado y que, ya por ignorancia o por negligencia, no se haya solicitado su registro. Estas situaciones no deben ser olvidadas pues significaría ello desconocer una realidad económica y quizás permitir el aprovechamiento indebido de una clientela ajena. Otra interpretación implicaría borrar del espectro marcario una parte importante de las nulidades marcarias ${ }^{13}$.

No obstante, insistimos, el uso por símismo no tiene ningún valor mientras no se halle vinculado a esa intensidad que genera una clientela, uso que debe efectuarse sin mala fe de querer aprovecharse del prestigio ajeno o induciendo a error al público por su confusión con otras marcas registradas con anterioridad ${ }^{14}$.

Ahondando en lo referente a esa clientela y a la calidad del producto o servicio que entraña una marca, si bien su única y verdadera función es la de distinguirlo, entre sus funciones secundarias ${ }^{15}$ se encuentra la de garantizar una calidad uniforme y es lo que se conoce como garantía, cuyo resultado no es otro que la relación repetitiva vendedor-comprador que provoca en el uso de una marca cierta constancia del producto ${ }^{16}$ o del servicio, haciéndolo característico y diferente y, por ende, se reitera haciéndose uniforme. Quien vuelve sobre una misma marca busca lo mismo que antes conoció, esa calidad uniforme del producto o servicio, aunque no sea esta ninguna obligación legal del titular de la marca por no haber norma que le exija fabricar productos o prestar servicios en forma idéntica a través de los años. No obstante, es interés propio del titular de la marca que el producto o servicio mantenga una calidad uniforme ${ }^{17}$ y que el consumidor la vuelva a elegir en forma constante y no opte por otra que sea competitiva. Las preferencias del público se conquistan con esfuerzo y pueden perderse con mucha facilidad. He aquí el interés del titular de la marca en mantener esa uniformidad en la calidad de lo que ofrece o incluso en mejorarla.

13 Otamendi, Jorge, Derecho de marcas, $4^{\mathrm{a}}$ edición actualizada y ampliada, Buenos Aires: Lexis Nexis - Abeledo-Perrot, 2002. p. 120.

14 Otamendi, Jorge, Derecho de marcas, 4a edición actualizada y ampliada, Buenos Aires: Lexis Nexis - Abeledo-Perrot, 2002. p. 14.

15 Mathély, Paul., Le droit français des signes distinctifs, París: Librarie du Journal des Notaires et des Avocats, 1984. p. 14.

16 Callman, Rudolf, The law or unfair competition, trademarks and monopolies, 4a edición, Illinois: Louis Altman, 1981. P. 9.

17 Otamendi, Jorge, Derecho de marcas, $4^{a}$ edición actualizada y ampliada, Buenos Aires: Lexis Nexis - Abeledo-Perrot, 2002. p. 10. 
Al decir de Jorge Otamendi, la marca es el único nexo que existe entre el consumidor del producto o el servicio y su titular. Esa marca es lo que el comprador ha de pedir y es lo que el titular de la misma tratará que pida ${ }^{18}$. Esa buena calidad que distingue a tal producto o servicio es lo que se denomina prestigio y es la que le otorga fama y la vuelve reconocida e interviene en una segunda instancia. Es decir, posteriormente al lanzamiento comercial del producto o servicio y dentro del supuesto de que este haya tenido una aceptación en el mercado, importa que la clientela no pueda confundirse como resultado de maniobras competitivas que "marcan" productos de origen y calidad distintos con el mismo signo" ${ }^{19}$.

\section{REGULACIÓN DEL DENOMINADO USO PREVIO EN MÉXICO}

En México, la situación es distinta ya que el denominado "uso previo de la marca" se encuentra previsto en el artículo 151 inciso II de la Ley de Propiedad Industrial (LPI) en vigor, conforme surge del texto de la nueva ley publicada el 27 de junio de 1991 en el órgano oficial de gobierno, denominado Diario Oficial de la Federación.

Tal artículo refiere al uso previo o marca de hecho expresamente en los siguientes términos: "El registro de una marca será nulo cuando: II. La marca sea idéntica o semejante en grado de confusión, a otra que haya sido usada en el país o en el extranjero con anterioridad a la fecha de presentación de la solicitud de la marca registrada y se aplique a los mismos o similares productos o servicios, siempre que, quien haga valer el mejor derecho por uso anterior, compruebe haber usado una marca ininterrumpidamente en el país o en el extranjero, antes de la fecha de presentación o, en su caso, de la fecha de primer uso declarado por el que la registró,...".

Menciona Jalife Daher al comentar la ley mexicana que entre las demandas de nulidad, el uso previo o marca de hecho es una de las figuras más invocadas por

18 Otamendi, Jorge, Derecho de marcas, 4a edición actualizada y ampliada, Buenos Aires: Lexis Nexis - Abeledo-Perrot, 2002. p. 11.

19 Bertone, Luis Eduardo y Cabanellas de las Cuevas, Guillermo, Derecho de marcas. Marcas, designaciones y nombres comerciales, $2^{a}$ edición actualizada, corregida y aumentada, Buenos Aires: Heliasta, 2003, tomo I, p. 332. 
su capacidad de resolver la disputa que generan dos derechos, uno por el uso y otro por el derecho adquirido al registrar una marca ${ }^{20}$.

De tal manera, siempre tendremos a varios sujetos diferentes, si no opuestos, que resultan interesados en un mismo derecho $y$, por ende, confrontados en el afán de poseer la titularidad de una marca determinada. Por un lado se encuentra el que ha usado la marca por un tiempo determinado y anterior al de la solicitud de registro y, por otro lado, está precisamente aquel que ha hecho tal solicitud de registro conforme al procedimiento legal establecido en el país del que se trate.

Este artículo se vincula con el número 92 fracción o inciso I de la misma ley mexicana ${ }^{21} y$, mientras este último opera como excepción, aquel es la manifestación adjetiva que permite controvertir el derecho obtenido por la vía del registro por un tercero. Ambos derechos parten de un mismo hecho generador (el uso de la marca), aunque se manifiesten de forma diferente 2223 .

El mencionado artículo 92, en su primera fracción o inciso regula la buena fe como limitación de los efectos del registro de una marca, cuando es igual o semejante en grado de confusión, estableciendo igualmente el mismo requisito del uso ininterrumpido antes de la fecha de presentación de la solicitud de registro o del primer uso declarado. De tal manera, no estamos frente a una violación del sistema atributivo en cuanto al derecho frente a una marca que goza de un registro sino que el sistema legal va más allá inclusive, confiriéndole derechos en

20 DAHER, Mauricio Jalife, Comentarios a la Ley de la Propiedad Industrial, 2a edición, México D.F.: Editorial Porrúa, 2009. p. 414, 258.

21 El artículo 92 fracción (o inciso) I de la Ley de Propiedad Industrial mexicana dispone : "El registro de una marca no producirá efecto algún contra : I. Un tercero que de buena fe explotaba en territorio nacional la misma marca u otra semejante en grado de confusión, para los mismos o similares productos o servicios, siempre y cuando el tercero hubiese empezado a usar la marca, de manera ininterrumpida, antes de la fecha de presentación de la solicitud de registro o del primer uso declarado en ésta. El tercero tendrá derecho a solicitar el registro de la marca, dentro de los tres años siguientes al día en que fue publicado el registro, en cuyo caso deberá tramitar y obtener previamente la declaración de nulidad de éste,". Resalta lo que este artículo expone acerca del plazo para solicitar el registro de una marca, con una redacción poco feliz considerando que más bien lo que se quiere estipular no es el tiempo del que dispone el propietario y poseedor de la marca para iniciar el trámite de registro, que es no prescribe, sino más bien y sobre todo el derecho que le corresponde para ejercer la acción de nulidad correspondiente, como bien lo expone el artículo correlativo, el número 151 in fine.

22 Al hacer el comentario, menciona el autor que esta excepción se vincula con la acción de nulidad por uso anterior.

23 DAHER, Mauricio Jalife, Comentarios a la Ley de la Propiedad Industrial, 2a edición, México D.F.: Editorial Porrúa, 2009. p. 260. 
cuanto a reconocimiento y garantías a aquellos comerciantes que han empleado una marca de buena fe y en forma ininterrumpida en el país, aunque en la práctica resulte un extremo difícil de probar.

La ley mexicana prevé además el caso de una marca de hecho o de uso previo que resulte semejante en grado de confusión a aquella registrada, por lo que el modelo mexicano rescata el derecho que poseen aquellas marcas de esa índole y que gozan de cierto prestigio entre el público consumidor, requiriendo en todos los casos, como lo señala la doctrina, el uso pacífico, público y continuado durante un período suficiente de tiempo a fin de que sea posible acreditar su difusión y reconocimiento vinculado con una clientela determinada ${ }^{24}$.

A contrario sensu, como se anticipó, la marca de hecho o de uso previo no podrá ser protegida ante terceros no autorizados que la han utilizado de buena fe, quienes por ende resultan protegidos frente a la inacción del titular de la marca de hecho o de uso previo que no ha recurrido al sistema registral o la publicidad correspondiente al mismo.

Cabe el comentario de que las marcas de uso previo o marcas de hecho no gozan de protección en el ámbito penal, a diferencia de las marcas registradas, contando solo con la que les confieren las acciones por competencia desleal, lo cual es fuertemente criticable. Ello en virtud de que el sistema penal aún requiere expresamente previa y efectiva inscripción de la marca para su tutela ${ }^{25}$. Aquí surge entonces una clara distinción a favor de la marca registrada, haciéndose notar la ventaja del sistema registral frente a la buena fe del propietario de la marca de hecho o de uso previo, lo cual no es a todas luces acertado, considerando que el ámbito penal no debería distinguir entre el fundamento de buena fe que ampara a este último tipo de marca frente a la legalidad de la registrada, más aún si ha quedado admitido que no son ilegítimas y, en cada caso específico, se haya probado el valor adquirido en razón del prestigio comercial, así como el uso ininterrumpido.

24 Bertone, Luis Eduardo y Cabanellas de las Cuevas, Guillermo, Derecho de marcas. Marcas, designaciones y nombres comerciales, $2^{a}$ edición actualizada, corregida y aumentada, Buenos Aires: Heliasta, tomo I, 2003, p. 312.

25 En la legislación argentina véase el mencionado artículo 4 de la Ley 22.362. 
En México, la misma LPI, a través de su artículo 223, se ocupa de regular los delitos relativos a la propiedad industrial, los que se perseguirán por querella de la parte ofendida ${ }^{26}$.

\title{
VINCULACIÓN DE LA LEGISLACIÓN MEXICANA CON LA JURISPRUDENCIA ARGENTINA
}

En México, el tema aún no ha logrado alcanzar importante difusión y aún no existen precedentes jurisprudenciales. En la jurisprudencia argentina donde, recordemos, son los tribunales civiles los que dirimen cuestiones relativas a la propiedad intelectual, un fallo en amparo señala respecto a tal legitimidad y a la cuestión del prestigio alcanzado por la marca de hecho o de uso previo:

\author{
MARCAS. DE heCHO. USO. PUBLICIDAD. CLIENTELA. TUTELA \\ LEGAL. FICHA N 5869. La firma L. es titular -al menos hasta ahora- de \\ una "marca de hecho". Las marcas de esa especie, que ciertamente no \\ son ilegitimas, son merecedoras de tutela jurídica cuando, a su amparo, \\ se ha desarrollado una actividad comercial lícita y a través de ella su
}

26 "Artículo 223.- Son delitos: I. Reincidir en las conductas previstas en las fracciones II a XXII del artículo 213 de esta Ley, una vez que la primera sanción administrativa impuesta por esta razón haya quedado firme; II. Falsificar, en forma dolosa y con fin de especulación comercial, marcas protegidas por esta Ley; III. Producir, almacenar, transportar, introducir al país, distribuir o vender, en forma dolosa y con fin de especulación comercial, objetos que ostenten falsificaciones de marcas protegidas por esta Ley, así como aportar o proveer de cualquier forma, a sabiendas, materias primas o insumos destinados a la producción de objetos que ostenten falsificaciones de marcas protegidas por esta Ley; IV. Revelar a un tercero un secreto industrial, que se conozca con motivo de su trabajo, puesto, cargo, desempeño de su profesión, relación de negocios o en virtud del otorgamiento de una licencia para su uso, sin consentimiento de la persona que guarde el secreto industrial, habiendo sido prevenido de su confidencialidad, con el propósito de obtener un beneficio económico para sí o para el tercero o con el fin de causar un perjuicio a la persona que guarde el secreto; $V$. Apoderarse de un secreto industrial sin derecho y sin consentimiento de la persona que lo guarde o de su usuario autorizado, para usarlo o revelarlo a un tercero, con el propósito de obtener un beneficio económico para sí o para el tercero o con el fin de causar un perjuicio a la persona que guarde el secreto industrial o a su usuario autorizado, y VI. Usar la información contenida en un secreto industrial, que conozca por virtud de su trabajo, cargo o puesto, ejercicio de su profesión o relación de negocios, sin consentimiento de quien lo guarde o de su usuario autorizado, o que le haya sido revelado por un tercero, a sabiendas que éste no contaba para ello con el consentimiento de la persona que guarde el secreto industrial o su usuario autorizado, con el propósito de obtener un beneficio económico o con el fin de causar un perjuicio a la persona que guarde el secreto industrial o su usuario autorizado. Los delitos previstos en este artículo se perseguirán por querella de parte ofendida". 
titular ha conseguido formar una clientela. En efecto, la circunstancia de que los signos marcarios no hubieran, por el momento, obtenido el registro que contempla el art. $4^{\circ}$, Ley 22.362 , no es razón que las prive de toda protección contra actos de espurio acercamiento o lisa y llanamente de "piratería marcaria", enderezados a lucrar indebidamente con el prestigio ganado por la marca de hecho desviando ilícitamente el derecho a una clientela formada dentro de los géneros legales. Lionel's SRL s/medidas cautelares. Causa $N^{\circ} \quad 6080 / 98$. Cámara CIVCOMFED: 2. Vocos Conesa - Mariani de Vidal 24/11/98.

Además de ser esta una causa relevante para la figura en estudio, se destaca por plasmar el artículo 50 del Acuerdo sobre los Aspectos de los Derechos de Propiedad Intelectual relacionados con el Comercio (ADPIC $)^{27}$ al prescribir la orden de cese de uso temporal o provisional que prevé tal artículo. En efecto, en este

27 Este artículo se encuentra dentro del Acuerdo en la Sección 3 que establece las Medidas provisionales y expresa cuanto sigue: "1. Las autoridades judiciales estarán facultadas para ordenar la adopción de medidas provisionales rápidas y eficaces destinadas a: a) evitar que se produzca la infracción de cualquier derecho de propiedad intelectual y, en particular, evitar que las mercancías ingresen en los circuitos comerciales de la jurisdicción de aquéllas, inclusive las mercancías importadas, inmediatamente después del despacho de aduana; b) preservar las pruebas pertinentes relacionadas con la presunta infracción. 2. Las autoridades judiciales estarán facultadas para adoptar medidas provisionales, cuando ello sea conveniente, sin haber oído a la otra parte, en particular cuando haya probabilidad de que cualquier retraso cause daño irreparable al titular de los derechos, o cuando haya un riesgo demostrable de destrucción de pruebas. 3. Las autoridades judiciales estarán facultadas para exigir al demandante que presente las pruebas de que razonablemente disponga, con el fin de establecer a su satisfacción con un grado suficiente de certidumbre que el demandante es el titular del derecho y que su derecho es objeto o va a ser objeto inminentemente de infracción, y para ordenar al demandante que aporte una fianza o garantía equivalente que sea suficiente para proteger al demandado y evitar abusos. 4. Cuando se hayan adoptado medidas provisionales sin haber oído a la otra parte, éstas se notificarán sin demora a la parte afectada a más tardar inmediatamente después de ponerlas en aplicación. A petición del demandado, en un plazo razonable contado a partir de esa notificación se procederá a una revisión, en la que se le reconocerá el derecho de audiencia, con objeto de decidir si deben modificarse, revocarse o confirmarse esas medidas. 5. La autoridad encargada de la ejecución de las medidas provisionales podrá exigir al demandante que presente cualquiera otra información necesaria para la identificación de las mercancías de que se trate. 6. Sin perjuicio de lo dispuesto en el párrafo 4, las medidas provisionales adoptadas al amparo de los párrafos 1 y 2 se revocarán o quedarán de otro modo sin efecto, a petición del demandado, si el procedimiento conducente a una decisión sobre el fondo del asunto no se inicia en un plazo razonable que habrá de ser establecido, cuando la legislación de un Miembro lo permita, por determinación de la autoridad judicial que haya ordenado las medidas, y que a falta de esa determinación no será superior a 20 días hábiles o 31 días naturales, si este plazo fuera mayor. 7. En los casos en que las medidas provisionales sean revocadas o caduquen por acción u omisión del demandante, o en aquellos casos en que posteriormente se determine que no hubo infracción o amenaza de infracción de un derecho de propiedad intelectual, las autoridades judiciales estarán facultadas para ordenar al demandante, previa petición del demandado, que pague a éste una indemnización adecuada por cualquier daño causado por esas medidas. 8. En la medida en que puedan ordenarse medidas provisionales a resultas de procedimientos administrativos, esos procedimientos se atendrán a principios sustancialmente equivalentes a los enunciados en esta sección". 
caso, el titular de la marca de hecho de juguetes Gloria solicitó la aplicación del acuerdo internacional $y$, por ende, el cese de uso de la marca que idénticamente estaba siendo utilizada por el demandado, Lionel's. El titular de Lionel's había solicitado el registro para su marca, en la que se había retirado la oposición a su registro. En cumplimiento a la normativa internacional, el tribunal hizo lugar a lo solicitado y ordenó la medida cautelar, reconociendo, como se nota de la jurisprudencia trascripta, no solo la viabilidad de las medidas precautorias a las marcas de hecho o de uso previo, independientemente de que tal marca se encuentre frente a otra con trámite de registro quizá muy avanzado ${ }^{27} \operatorname{sino}$ principalmente, el reconocimiento novedoso de la normativa internacional para el caso de las marcas de hecho o de uso previo.

Así, al analizar otro de los aspectos también criticables como lo es el hecho de que las marcas que nos ocupan tengan un acceso limitado a las medidas precautorias propias de la legislación de marcas, teniendo acceso a aquellas previstas en forma genérica por las normas procesales y a las que prevé el ADPIC, señalan al respecto.

Bertone y Cabanellas respecto al fallo antedicho de Lionel's S.R.L. de la Cámara Nacional de Apelación en lo Civil y Comercial Federal que reza que, en forma general, las marcas de hecho ciertamente no son ilegítimas, son merecedoras de tutela jurídica cuando, a su amparo, se ha desarrollado una actividad comercial lícita y a través de ella su titular ha conseguido formar una clientela, añadiendo que el titular de una marca de hecho o de uso previo, en trámite de registro, tiene derecho a reclamar el cese de uso de una marca similar o confundible ${ }^{28}$ y estableciendo asimismo la posibilidad de recurrir a las acciones penales por competencia desleal, basadas en el artículo 159 del Código Penal argentino ${ }^{29}$.

Otra jurisprudencia argentina, relacionada con la citada recientemente, señala sobre la legitimidad de esta figura:

28 Ya que aquí lo importante, reiteramos, es el prestigio de la marca y la clientela que ha logrado conformar, no siendo absolutamente relevante que esté pendiente el otorgamiento de otro registro.

29 Bertone, Luis Eduardo y Cabanellas de las Cuevas, Guillermo, Derecho de marcas. Marcas, designaciones y nombres comerciales, $2^{a}$ edición actualizada, corregida y aumentada, Buenos Aires: Heliasta, tomo I, 2003, p. 312. 
MARCAS: DE HECHO. AMPARO LEGAL. ANTECEDENTE DE LA SALA

2. - En numerosas oportunidades esta Sala ha decidido que el titular de una "marca de hecho" es digno de amparo legal al menos por aplicación de los principios generales del derecho y en ciertos casos específicamente por el art. 953 C.C. (confr. causa 6080/98 "Lionel's s/ medidas cautelares", del 24.11.98), siendo uno de sus derechos oponerse a un registro marcario solicitado cuando estima que puede suscitar confusiones afectando su interés particular y el interés general de los consumidores (art. $4^{\circ}$ Ley 22.362), comportando un problema distinto lo atinente a si la marca invocada sin registrar reúne en definitiva los recaudos que hacen a su tutela.- 5.215/99 GAMARSU SRL C/ SEVERINO EDGARDO DANIEL S/CESE DE OPOSICION AL REGISTRO DE MARCA - 19/08/2008. CNCIV Y COMFED - Sala 2, Dr. Eduardo Vocos Conesa - Dr. Santiago Bernardo Kiernan.

Volviendo a la fuente legal, al respecto la ley mexicana llega mucho más lejos con su artículo 92 fracción I de la LPI, como se advirtió, al no limitar los casos de marcas similares a la acción penal por competencia desleal y establecer en el mencionado artículo la posibilidad de verse protegido ab initio el titular ante otra "marca semejante en grado de confusión" que amenace el prestigio de su marca de hecho o de uso previo, siendo la "marca semejante en grado de confusión" aquella que estructural, gramatical, fonética, ortográfica y visualmente se asemeja a otra previamente registrada y que se aplica a los mismos productos o servicios que ampara aquélla ${ }^{30}$.

El carácter distintivo y presupuesto fundamental de la marca de hecho o de uso previo, como se expresó, es el uso suficientemente prolongado, previo, público y pacífico de la misma y en menor medida, pero con no menos importancia, se encuentra el reconocimiento por el público consumidor, el cual no resulta sino de aquel mencionado uso prolongado ya que solo el tiempo es el que puede conferir fama y prestigio a un producto, generalmente en virtud de su calidad reconocida. A contrario sensu, la marca de hecho o de uso previo se tornará más débil e incluso se perderá si se interrumpe tal uso o disminuye su difusión, haciendo que el público ya no la reconozca con facilidad.

El simple uso le da una protección importante, contra la cual solo puede argumentarse la falta de prestigio, que el uso haya sido interrumpido o la mala

30 Castrejón García, Gabino Eduardo, Ley de la propiedad industrial, $1^{\text {a }}$ edición, México D.F.: Cárdenas Velasco Editores S.A. de C.V., 2004. P. 344. 
fe del titular de hecho, en cuyo caso estaríamos más bien frente a una situación de pretensión de ventaja de un esfuerzo no propio sino más bien ajeno o de la intención de dificultar la identificación de bienes y servicios dentro de un régimen de competencia leal.

Al respecto, puntualicemos que, conforme se ha visto, la facultad de registrar el signo es inherente al interesado y no es obligatoria ni es indispensable para su uso, siendo entonces permitido el uso de la marca no registrada -o incluso de aquella no registrable-, siempre y cuando no se afecten derechos de terceros y tal uso sea lícito, de buena fe. Sin embargo, ante la necesidad de ejercer su defensa, la que se halla vinculada estrechamente con el uso de esa marca, es necesario insistir, tal como lo sostiene la doctrina, que la autoridad competente para determinar la buena fe no puede ser en ningún caso la instancia administrativa que tramita los registros de marcas (el Instituto Mexicano de la Propiedad Industrial en México o el Instituto Nacional de la Propiedad Industrial en Argentina) sino más bien la judicial o alguna administrativa que cumpla la tarea de dictaminar sobre lealtad comercial (Dirección Nacional de Lealtad Comercial, en Argentina) ${ }^{31}$.

\section{INTERÉS JURÍDICO DE LA MARCA DE HECHO O DE USO PREVIO Y EFECTOS DE LA NULIDAD DEL REGISTRO MARCARIO NULIFICADO}

A fin de contar con interés jurídico dentro de la figura de la nulidad para efectos marcarios es importante ser titular de los derechos que se presuponen infringidos o, en su defecto, que tales derechos sean tutelados por la colectividad. En el ámbito del derecho marcario, no es menor el concepto de interés legítimo y deviene en fundamental como presupuesto para ejercer la acción de nulidad a fin de defender la marca y de manera a evitar el "aventurerismo marcario" que señala el autor Aracama Zorraquín ${ }^{32}$ al hacer hincapié en la importancia de

31 Bertone, Luis Eduardo y Cabanellas de las Cuevas, Guillermo, Derecho de marcas. Marcas, designaciones y nombres comerciales, $2^{a}$ edición actualizada, corregida y aumentada, Buenos Aires: Heliasta, tomo II, 2003, p. 19, 20.

32 El autor realiza un análisis profundo de la problemática del interés legítimo en general en el derecho de marcas en su obra "Sobre el concepto de interés legítimo en la ley de marcas", La Ley, Buenos Aires, Argentina, 1989-E, Sección Doctrina. 
recordar que la marca tiene la principal función de garantizar tanto el origen como la calidad de un producto o servicio ${ }^{33}$.

De esta manera, opina Castrejón García que tal interés jurídico puede resultar público o privado y el que se vincula con la marca de hecho o de uso previo resulta preponderantemente privado $y$, en menor medida, público. El interés público aquí radica en la fama o prestigio con que la clientela identifica el producto o servicio, por lo que la irregularidad o contravención de la ley de la materia en su comercialización afecta directamente al consumidor final, es decir, el engaño que encierra un signo distintivo, como lo es la marca, provoca detrimento no solo económico sino social. El interés privado se acentúa en la materia que nos ocupa, en donde se considera nulo el otorgamiento de un registro cuando se afectan derechos de los particulares, sean estos personas físicas o morales ${ }^{34}$, afectándose por ende el interés jurídico referido.

En nuestra opinión, frente a la legislación marcaria, más bien convendría referirse al interés legítimo del propietario de la marca en análisis, el cual no resulta sino de la propia legislación que lo ampara.

La jurisprudencia argentina nuevamente señala sobre el interés legítimo:

MARCAS: DE HECHO. TUTELA JURISDICCIONAL. VALOR A LA MARCA USADA. ANTECEDENTES DEL TRIBUNAL Y DOCTRINA En anteriores ocasiones el Tribunal ha reconocido que, en situaciones excepcionales, las "marcas de hecho", intensamente explotadas y que a su amparo han formado una clientela, pueden merecer alguna tutela jurisdiccional (cfr. esta Sala, causas 54653/95 del 27.6.96 y 4564/01 del 4.10.01; Sala II, causas 8858 del 25.8.92, 296 del 27.10.92, 4343 del 27.8 .93 y 6080/98 del 24.11.98). Lo contrario, importaría sumir al titular de una marca de las características aludidas en un estado de desprotección frente al ilegítimo uso de la misma marca por un tercero, para aprovechar el prestigio ajeno o desviar la clientela (cfr. esta Sala, causa 4564 cit.). La propia ley de marcas -en su art. $4^{\circ}$ - dispone que "para ejercer el derecho de oposición a su registro o a su uso, se requiere un interés legítimo...del oponente". De donde se sigue que el titular de una marca "de hecho", empleada con las características antes

33 Zorraquín, Ernesto Aracama, et al. Derecho de Marcas, Buenos Aires: Ciudad Argentina, 1999. p. 174.

34 Castrejón García, Gabino Eduardo, Ley de la propiedad industrial, $1^{\text {a }}$ edición, México D.F.: Cárdenas Velasco Editores S.A. de C.V., 2004. P. 346/347. 
descriptas, tiene derecho a peticionar el cese de uso de una marca similar o confundible, desde que el Tribunal, en numerosas ocasiones, ha reconocido valor a la marca usada (cfr. esta Sala, doctr. causas 1980 del 16.10.87, 4979 del 5.2.88 y 54653/95 del 27.6.96, entre otras; Sala II, causa 4343 cit.; Otamendi, J., "Tratado de marcas", Bs. As., 1989, p. 13, punto 1.4), lo que claramente significa que a su titular se le ha admitido la posesión de un "interés legítimo", tal como lo exige la Ley 22.362. Dicha solución que se desprende sin esfuerzo interpretativo del precitado art. $4^{\circ}$, encuentra también apoyo en el principio rector del art. 953 del Código Civil que veda los actos inmorales o contrarios a las buenas costumbres (cfr. Sala II, causa 4343 cit.). 3.063/07 - LABORATORIOS BAGO S.A. C/ LABORATORIO E.J. GEZZI S.R.L. S/ MEDIDAS CAUTELARES - Fecha: 19/04/2007. CNCIV Y COMFED - SALA 1., Dr. Francisco de las Carreras - Dr. Martín Diego Farrell.

En cuanto a los efectos del registro marcario nulificado se enumeran en los siguientes:

a) Cesación de derechos.

b) Carencia inmediata de interés jurídico otorgado originalmente al titular de un registro nulo.

c) Establecimiento de medidas tendientes al retiro de los productos o servicios del mercado nacional que sean identificados con un registro marcario nulo.

d) Aplicación en su caso de sanciones o ejercicio de acción penal para el que era conocido como el titular de un registro nulificado.

La nulidad resulta relativa en cuanto al lapso que se otorga hasta la resolución de la nulidad y la cesación de los derechos y deviene en absoluta cuanto la resolución que la declara queda legalmente firme ${ }^{35}$.

Interpretando correctamente la legislación mexicana, la interposición de la demanda será procedente solamente a petición de parte $y$, excepcionalmente, de oficio en los casos en los que el gobierno manifieste algún interés directo, en salvaguarda del consumidor y, por qué no, de la economía pública, considerando que la invasión de marcas por terceros ajenos requiere forzosamente para su

35 Castrejón García, Gabino Eduardo, Ley de la propiedad industrial, $1^{\text {a }}$ edición, México D.F.: Cárdenas Velasco Editores S.A. de C.V., 2004. P. 347. 
defensa la instancia o petición de su legítimo titular. Tal es lo que establecía la anterior Ley de Invenciones y Marcas mexicana, al mencionar expresamente en su artículo 151 la petición de parte: "Art. 151. La declaración de nulidad o extinción del registro de una marca, en los casos en que se requiera, se hará administrativamente por la Secretaría de Comercio y Fomento Industrial de oficio, a petición de parte o del Ministerio Público Federal, cuando tenga algún interés de la Federación" y al día de hoy, la actual LPI recrea en su artículo 155 tal disposición al expresar: "La declaración de nulidad, caducidad o cancelación del registro de una marca, se hará administrativamente por el Instituto de oficio, a petición de parte o del Ministerio Público Federal, cuando tenga algún interés la Federación". Además, la jurisprudencia ha sido clara al respecto en este país a favor del interés jurídico descrito ${ }^{36}$ y lo que ha querido pretender no es sino recalcar que en todo caso la acción de nulidad no podrá ser jamás interpuesta por aquel que no lo posea o por el que invoque derechos que no le pertenecen.

\section{OTROS ASPECTOS DE LA MARCA DE HECHO O DE USO PREVIO. BREVE REFERENCIA AL CASO EN BRASIL: EL DERECHO DE PRECEDENCIA}

En cuanto a reformas legislativas, un aspecto a hacer notar es el plazo concedido por la legislación (mexicana) a favor del poseedor del mejor derecho de uso. Es que el tiempo que otorga la ley -tres años- para registrar o interponer la acción de nulidad resulta notoriamente insuficiente a la hora de evaluar las posibilidades del propietario de la marca de hecho o de uso previo de obtener éxito en su acción, y también resulta evidente la escasez de tiempo con que cuenta para tomar conocimiento de que el registro de su marca ha sido otorgado a un tercero, por lo que sería muy acertada una reforma legislativa que, en el caso mexicano, equipare a cinco años el tiempo que tiene el afectado para interponer la demanda, tal como ocurre con los demás apartados (incisos) del artículo

36 Cfr. Jurisprudencia mexicana del Cuarto Tribunal Colegiado en Materia Administrativa del Primer Circuito. Amparo en revisión 1944/92. Suave Piel, S.A. 15 de octubre de 1992. Unanimidad de votos. Ponente: Hilario Bárcenas Cháves. Secretario: Fernando A. Ortiz Cruz. Semanario Judicial. Octava Época. Tomo XI. Marzo 1993. Tribunales Colegiados. Pág. 222. 
$151^{37}$ que inclusive prevén un margen indeterminado de tiempo para el caso del otorgamiento de un registro marcario en contravención a la ley o por error (art. 151 apartados o incisos I y V).

Otra fuerte crítica consiste en que la fracción I del artículo 92 de la LPI mexicana no precisa si la excepción de tutela a favor de quien ostenta mejor derecho sobre el uso de una marca -no sobre la titularidad- opera o más bien cesan sus efectos y parece concluirse al respecto que no existe razón alguna para considerar que la excepción debe cesar al incumplirse el plazo de tres años sin que se interponga una acción de nulidad, y tal problema se resuelve únicamente con la idea de que no sería deseable la situación de coexistencia de dos marcas, por lo que la marca de hecho o de uso previo caerá por sí misma por falta de acción para impedir la presencia de la competidora al haberse cumplido el término legal previsto ${ }^{38}$ pero a sabiendas que, a su vez, la marca registrada tampoco podía haber atacado a la que presenta el mejor derecho de uso en virtud a la excepción prevista en la fracción I del artículo 92, no siendo entonces la redacción legislativa la más acertada.

Insistimos, la reforma legislativa deberá incluir una redacción que no dé lugar a equívocos pues, por otra parte, la declaración de nulidad, por un lado, debería obtenerse en el exiguo plazo de tres años y, por otro lado, tal como la práctica lo ha demostrado, deberá anteceder a la solicitud del registro del propietario y poseedor de buena fe siendo que, en realidad, tal declaración de nulidad será posterior a la solicitud del registro correspondiente, solicitud que devendrá por ende en presupuesto y fundamento de su interés jurídico, una vez publicado el registro en disputa en el órgano oficial, momento en el que comenzará a correr el plazo de tres años para interponer tal demanda de nulidad regulada por la fracción (o inciso) II del mencionado artículo 151 de la LPI.

En términos generales, como se mencionó, la disposición contenida en esta fracción puede interpretarse como la manifestación adjetiva de la excepción

37 El último apartado del artículo 151 de la Ley de Propiedad Industrial de México expone: "Las acciones de nulidad que se deriven del presente artículo podrán ejercitarse dentro del plazo de cinco años, contado a partir de la fecha en que surta sus efectos la publicación del registro en la Gaceta, excepto las relativas a las fracciones I y IV que podrán ejercitarse en cualquier tiempo y a la fracción II que podrá ejercitarse dentro del plazo de tres años".

38 DAHER, Mauricio Jalife, Comentarios a la Ley de la Propiedad Industrial, 2a edición, México D.F.: Editorial Porrúa, 2009. p. 415. 
contenida en la fracción I del artículo 92 de la misma LPI mexicana ${ }^{39}$ y necesita de una mejor redacción que no permita lugar a equívocos y que, por sobre todo, dé oportunidad al propietario de la marca de poder defenderla en un plazo más amplio.

En fin, corresponde no dejar de mencionar que existe además la posibilidad de que la nulidad sea invocada por una marca de hecho o de uso previo que haya sido acreditada en territorio extranjero y que, por lo tanto, conceda derechos recíprocos entre aquellos países que reconocen en sus legislaciones esta figura, constituyéndose entonces en una clara excepción al principio de territorialidad que, como es sabido, es inherente y característico de la marca. Así, una vez reconocida cualquier marca de hecho o de uso previo en países extranjeros que admitan esta excepción, esta concesión permite a su titular demandar la nulidad de un registro concedido en cualquier otro territorio que igualmente reconozca la marca de hecho o de uso previo, por ejemplo, en territorio mexicano o argentino.

Se ha visto que algunos países adoptan el sistema atributivo, es decir y como se mencionó, el sistema a través del cual se otorga el derecho de propiedad industrial a quien registra la marca y prácticamente no es posible invocar derechos si no se cuenta con el registro previo, y otros el declarativo, aquel en el que la exclusividad sobre una marca es preexistente al registro: se logra primeramente con el uso y el registro viene a ser entonces una mera consecuencia. Lo cierto es que existe sí una tendencia actual casi generalizada al registro de la marca, pero algunas legislaciones combinan esta tendencia atributiva con la declarativa al dar cabida al uso previo inclusive como presupuesto para el registro marcario ${ }^{40} 41$.

El caso brasilero enfatiza que, incluso en contra de lo que pareciera pronunciar la doctrina y la jurisprudencia, la marca no registrada no está desprovista de

39 DAHER, Mauricio Jalife, Comentarios a la Ley de la Propiedad Industrial, 2a edición, México D.F.: Editorial Porrúa, 2009. p. 414/415.

40 Barbosa, Denise, Da proteção real da marca não registrada no Brasil, ene. 2013. Disponible en: <http://www.denisbarbosa.addr.com/arquivos/200/propriedade/da_protecao_real_marca_nao_registrada.pdf.> Acceso en: 29 set. 2016. P. 29.

41 En este sentido la autora Denise Barbosa indica: "Assim é que diz-se o sistema em que a exclusividade nasce do registro atributivo; aquele em que a propriedade nasce do uso, mas homologado pelo registro, declaratório". 
protección. El problema pareciera radicar en el hecho de la muy extensa y diversa protección que reciben las que sí están registradas ${ }^{42}$.

Brasil se inclina fuertemente a la tendencia atributiva como modo de adquisición de la propiedad de una marca. Sin embargo, en la ley de propiedad industrial pertinente, denominada Ley 9279 de 1996, la excepción aparece a través de la figura del Derecho de Precedencia mencionado en su artículo 129 y que es el derecho según el cual toda persona que de buena fe, al tiempo de la fecha de prioridad o depósito de una marca haya usado por lo menos durante seis meses una marca idéntica o semejante para distinguir un producto o servicio idéntico, semejante o afín, tendrá tal derecho sobre el registro ${ }^{43}$. En este caso, la invocada no debe ser necesariamente idéntica a la que se pretende registrar y basta con invocar una semejanza en actividades y una afinidad.

\section{CONCLUSION}

El interés público debe ser el presupuesto fundamental de todo signo distintivo como en este caso lo es la marca, es decir, la fama o prestigio con que la clientela identifica el producto o servicio, pues un engaño provocaría detrimento no solo económico sino social en lo tocante al derecho del consumidor. Así, sostengo en el ámbito de esta figura del Derecho de Propiedad Industrial, la marca, que su naturaleza deviene una concepción mixta, es decir, atributiva y declarativa: atributiva desde el punto de vista de su necesaria concesión por la autoridad, como potestad del Estado en su función administrativa, a fin de conceder la propiedad y crear un efecto erga omnes, pero sin desconocer su inherente característica declarativa por la que la misma preexiste al registro y este no viene más que "sellar" u homologar a tales efectos.

42 Barbosa, Denise, Da proteção real da marca não registrada no Brasil, ene. 2013. Disponible en: <http://www.denisbarbosa.addr.com/arquivos/200/propriedade/da_protecao_real_marca_nao_registrada.pdf.> Acceso en: 29 set. 2016. P. 1.

43 Siendo este tiempo mínimo previsto bastante exiguo. El texto de la Ley en mención reza en el Capítulo IV "De los derechos sobre la marca", Sección I "Adquisición", segundo apartado del artículo 129: "Toda pessoa que, de boa fé, na data da prioridade ou depósito, usava no País, há pelo menos 6 (seis) meses, marca idêntica ou semelhante, para distinguir ou certificar produto ou serviço idêntico, semelhante ou afim, terá direito de precedência ao registro". 
Así, la marca de hecho, de uso previo o el derecho de precedencia es la excepción legal prevista para aquel usuario de buena fe que invoca un uso anterior de la figura a modo de justo derecho de prevalencia en el registro.

En definitiva, este derecho es un derecho de prelación y de mejor derecho en el tiempo que es ejercido frente a un tercero, siempre y cuando el requisito de buena fe pueda comprobar el uso en fecha anterior a la denominada "fecha legal", que es la de la solicitud de registro. El requisito sine qua non será entonces el uso pacífico, público y continuado durante un período suficiente de tiempo a fin de que sea posible acreditar su difusión y reconocimiento vinculado con una clientela específica, como acertadamente advierte la legislación mexicana y más sumariamente lo cita la brasilera. Las reformas legislativas apuntadas en el caso mexicano se hacen imperantes para los aspectos procesales apuntados más arriba.

\section{BIBLIOGRAFÍA}

ARGENTINA. Ley argentina $N^{\circ} 3.975$ del 23 de noviembre de 1900 y Ley de Marcas y Designaciones $N^{\circ} 22.362$ del 26 de diciembre de 1980.

BARBOSA, Denise, Da proteção real da marca não registrada no Brasil, ene. 2013. Disponible en: <http://www.denisbarbosa.addr.com/arquivos/200/propriedade/da_protecao_ real_marca_nao_registrada.pdf.> Acceso en: 29 set. 2016.

BERTONE, Luis Eduardo y Cabanellas de las Cuevas, Guillermo, Derecho de marcas. Marcas, designaciones y nombres comerciales, $2^{\text {a }}$ edición actualizada, corregida y aumentada, Buenos Aires: Heliasta, 2003, t I y II.

BRASIL. Ley de Propiedad Industrial de Brasil Ley No 9.279 del 14 de mayo de 1996

CALLMAN, Rudolf, The law or unfair competition, trademarks and monopolies, 4a edición, Illinois: Louis Altman, 1981.

CASTREJÓN García, Gabino Eduardo, Ley de la propiedad industrial, $1^{\text {a }}$ edición, México D.F.: Cárdenas Velasco Editores S.A. de C.V., 2004.

DAHER, Mauricio Jalife, Comentarios a la Ley de la Propiedad Industrial, $2^{\text {a }}$ edición, México D.F.: Editorial Porrúa, 2009. 
JURISPRUDENCIAS de México y de Argentina.

MATHÉLY, Paul., Le droit français des signes distinctifs, París: Librarie du Journal des Notaires et des Avocats, 1984.

MÉXICO. Ley de Propiedad Industrial mexicana según nueva ley publicada el 27 de junio de 1991 en el Diario Oficial de la Federación

OMC. Acuerdo sobre los Aspectos de los Derechos de Propiedad Intelectual relacionados con el Comercio (ADPIC).

OTAMENDI, Jorge, Derecho de marcas, $4^{\text {a }}$ edición actualizada y ampliada, Buenos Aires: Lexis Nexis - Abeledo-Perrot, 2002.

ZORRAQUÍN, Ernesto Aracama, et al. Derecho de Marcas, Buenos Aires: Ciudad Argentina, 1999.

Recebido em: agosto/2017

Aprovado em: dezembro/2017 